\title{
PERENCANAAN JARINGAN METRO ETHERNET KOTA BANDUNG TAHUN 2028 MENGGUNAKAN ALGORITMA DYSART AND GEORGANAS DAN ALGORITMA BRUTE FORCE SERTA PERAMALAN TRAFIK DENGAN METODE PEMBOBOTAN
}

\author{
Triya Eva Widyasari ${ }^{*}$, Sukiswo dan Ajub Ajulian Zahra \\ Departemen Teknik Elektro, Universitas Diponegoro \\ Jl. Prof. Sudharto, SH, Kampus UNDIP Tembalang, Semarang 50275, Indonesia \\ ${ }^{*}$ E-mail: triyaeva15@gmail.com
}

\begin{abstract}
Abstrak
Perkembangan kebutuhan komunikasi data menuntut sebuah jaringan yang handal dengan performansi yang lebih baik. Jaringan metro ethernet dapat dijadikan suatu solusi yang bisa dimanfaatkan dalam menyalurkan paket data, karena metro ethernet merupakan jaringan backbone yang jarak jangkauannya luas berskala perkotaan. Pada penelitian ini dirancang sebuah jaringan metro ethernet Kota Bandung yang dapat bertahan hingga tahun 2028. Perencanaan jaringan menggunakan algoritma Dysart and Georganas untuk menentukan node konsentrator dan penyelesaian Travelling Salesman Problem (TSP) menggunakan algoritma Brute Force. Metode peramalan trafik menggunakan point to point forecast dengan pembobotan Rapp's 1, Rapp's 2 dan Australian Telecom untuk mengetahui pertumbuhan trafik setiap tahun dan memperkirakan volume trafik pada tahun 2028. Penentuan kapasitas link merujuk pada standar trafik load PT Telkom Indonesia dengan batas utilisasi 55\%. Hasil penelitian menunjukkan bahwa trafik di setiap link selalu meningkat antara 173 Mbps hingga 6.908 Mbps tiap tahun. Dari kapasitas yang telah ditentukan utilisasi trafik dua arah terendah 30\% dan tertinggi 53\%, hal tersebut sudah sesuai dengan standar yang ditetapkan.
\end{abstract}

Kata kunci: metro ethernet, perencanaan, trafik, konsentrator, TSP, kapasitas

\begin{abstract}
The development of data communication needs requires a reliable network with better performance. The metro ethernet network can serve solutions that can be used in distributing data packages, because the metro is a backbone network that has a wide range of coverage on an urban scale. In this study, a Bandung City metro ethernet network was designed that can last until 2028. Network planning uses the Dysart and Georganas algorithms to identify concentrator node and resolve Traveling Salesman Problems (TSP) using a Brute Force algorithm. Traffic forecasting method uses point-topoint forecast with Rapp's 1,Rapp's 2 and Australian Telecom weighting to determine traffic growth every year and estimated traffic volume in 2028. Link capacity determination refers to the traffic load standards of PT Telkom Indonesia with a utilization limit of 55\%. The results show that link traffic increases $173 \mathrm{Mbps}$ to $6.908 \mathrm{Mbps}$ every year. From the capacity that has been set, the lowest two-way traffic utilization is $30 \%$ and the highest is $53 \%$, it is in accordance with the standards set
\end{abstract}

Keywords:, metro ethernet, planning, traffic, concentrator, TSP, capacity

\section{Pendahuluan}

Pada sistem transmisi jaringan yang handal harus dapat menjaga aliran data sehingga tidak terjadi kemacetan atau bahkan overload. Sehingga masing-masing service provider berusaha membangun sistem transmisi yang dapat mencukupi aliran data serta toleran dan tahan terhadap kesalahan. Namun perkembangan yang dilakukan oleh masing-masing service provider masih kurang efektif dan efesien sehingga diperlukan sistem transmisi untuk semua service provider. Salah satu sistem transmisi yang saat ini sedang berkembang adalah metro ethernet yang merupakan pengembangan dari teknologi ethernet pada local area network (LAN). Bandung sebagai salah satu kota besar yang ada di Indonesia dengan penduduk yang bertambah setiap tahun. Layaknya masyarakat perkotaan, penduduk usia produktif di Kota Bandung menjadikan internet sebagai kebutuhan yang utama yang menjadikan penduduk usia produktif sebagai penyumbang kenaikan aliran data trafik internet. Begitu 
juga keberadaan perguruan tinggi serta perindustrian yang terus berkembang ikut memberikan kontribusi terhadap kenaikan alliran trafik di Kota Bandung. Oleh karena itu, diperlukan peramalan kebutuhan trafik berdasarkan penduduk usia produktif, perguruan tinggi dan industri yang berada di kota Bandung.

Perencanaan jaringan metro ethernet dan peramalan (forecasting) trafik di Kota Bandung pada penelitian ini menggunakan estimasi point to point dengan teori pembobotan serta penentuan kapasitas link yang sesuai untuk trafik yang telah diramalkan akan menjadi fokus utama penelitian ini. Penelitian tentang perencanaan jaringan telah dilakukan oleh Devi Tiarani P [1] namun jaringan yang digunakan bukanlah metro ethernet melainkan jaringan DWDM. Teknik peramalan trafik juga telah dilakukan oleh Satya Yoga [2] dan Mona Apriani [3]. Satya Yoga [2] melakukan peramalan trafik dengan metode kruithof's double factor, sedangkan Mona Apriani [3] menggunakan jumlah penduduk dan pendapatan perkapita. Penelitian yang membahas mengenai metro ethernet juga dilakukan oleh Bayu Fitranto [4] dan Usmiati [5]. Namun detail pembahasan pada penelitian Bayu Fitranto [4] adalah untuk mengurangi terjadinya collision domain yang dapat mengakibatkan broadcast storm serta mengatasi kondisi looping dan duplicate paket pada jaringan metroethernet Head Office Bank Danamon Indonesia Ciputra World, sedangkan Usmiati [5] membahas tentang jaringan backbone metro ethernet ruas Ancol-Pasar Seni Area Jakarta Utara.

Berdasarkan hal di atas, maka dilakukan penelitian untuk merencanaan jaringan metro ethernet dan peramalan (forecasting) trafik di Kota Bandung menggunakan estimasi point to point dengan teori pembobotan serta penentuan kapasitas link yang sesuai untuk trafik yang telah diramalkan

\section{Metode \\ 2.1. Diagram Alir Sistem}

Sistem yang dirancang merupakan perencanaan jaringan backbone Kota Bandung beserta peramalan trafik untuk kebtuhan tahun 2028. Diagram alir sistem yang dibuat ditampilkan pada Gambar 1, diagram alir ini berfungsi sebagai tahapan dalam pembuatan penelitian ini. Tahap awal dari perencanaan jaringan adalah penentuan node dan topologi jaringan menggunakan algoritma Dysart and Georganas dan algoritma Brute Force sehingga membentuk jaringan multi ring dengan satu node konsentratror. Tahap selanjutnya adalah peramlan trafik menggunakan point to point forecast dengan metode pembobotan.

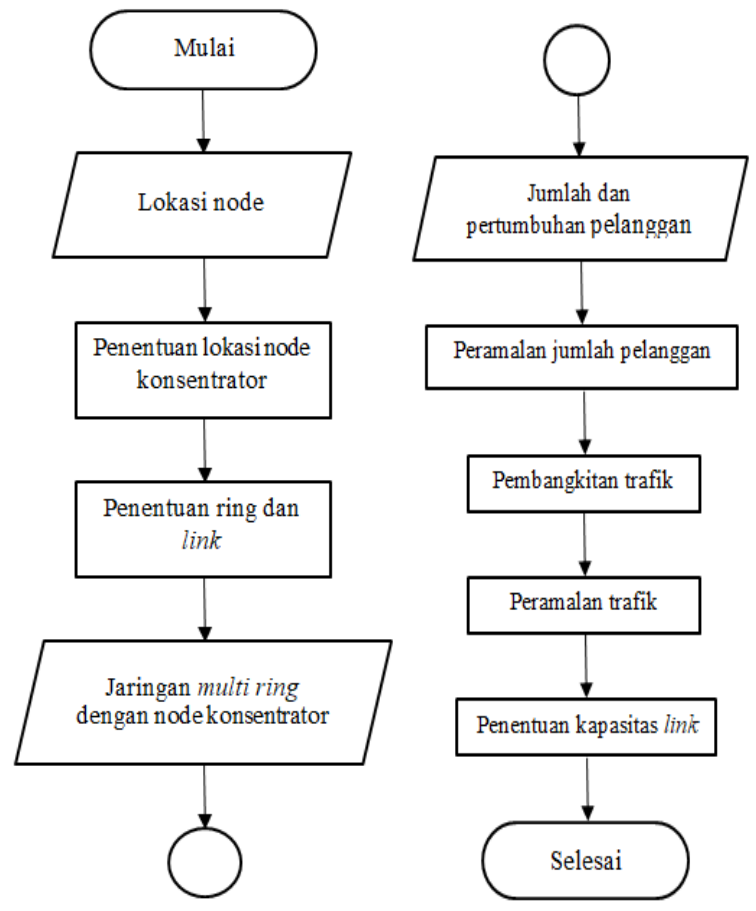

Gambar 1. Diagram Alir Perencanaan Sistem

\subsection{Perencanaan Jaringan \\ 2.2.1. Penentuan Node}

Pada jaringan metro ethernet yang sudah ada, jaringan metro ethernet Kota Bandung meliputi seluruh daerah operasi PT Telkom Regional 3 Jawa Barat. Berdasarkan Rencana Tata Ruang dan Wilayah (RTRW) Kota Bandung tahun 2011-2031 maka dilakukan pembatasan jumlah node pada penelitian ini dengan dipilihnya 9 node karena perencanaan jaringan metro ethernet pada penelitian ini untuk tahun 2028. Node yang dipilih dapat dilihat pada Gambar 2. dan pembagian wilayah node dapat dilihat pada Tabel 1.

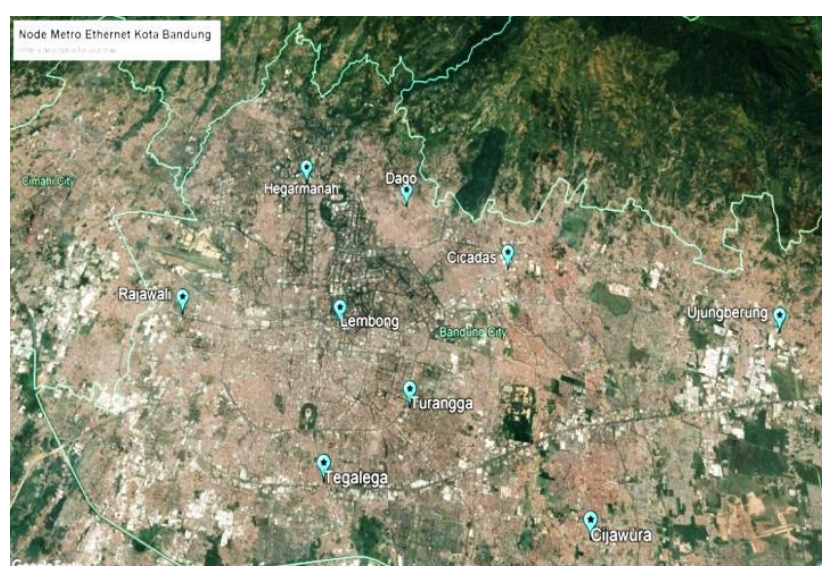

Gambar 2. Lokasi dan Koordinat Node Metro Ethernet Kota Bandung 
TRANSIENT, VOL. 7, NO. 4, DESEMBER 2018, ISSN: 2302-9927, 1020

Tabel 1. Pembagian jangkauan wilayah node

\begin{tabular}{|c|c|c|c|c|c|}
\hline Node & Wilayah jangkauan & Node & Wilayah jangkauan & Node & Wilayah jangkauan \\
\hline UBR & $\begin{array}{l}\text { Ujungberung } \\
\text { Cinambo } \\
\text { Cibiru } \\
\text { Panyileukan } \\
\text { Gedebage }\end{array}$ & TGA & $\begin{array}{l}\text { Astana Anyar } \\
\text { Bojongloa Kaler } \\
\text { Bojongloa Kidul }\end{array}$ & CCD & $\begin{array}{l}\text { Cibeunying Kidul } \\
\text { Mandalajati } \\
\text { Antapani }\end{array}$ \\
\hline HGM & $\begin{array}{l}\text { Cidadap } \\
\text { Sukasari } \\
\text { Sukajadi }\end{array}$ & RJW & $\begin{array}{l}\text { Andir } \\
\text { Bandung Kulon } \\
\text { Babakan Ciparay }\end{array}$ & LBG & $\begin{array}{l}\text { Sumur Bandung } \\
\text { Cicendo } \\
\text { Batununggal } \\
\text { Kiaracondong }\end{array}$ \\
\hline CJA & $\begin{array}{l}\text { Arcamanik } \\
\text { Rancasari } \\
\text { Buah Batu }\end{array}$ & DGO & $\begin{array}{l}\text { Coblong } \\
\text { Bandung Wetan } \\
\text { Cibeunying Kaler }\end{array}$ & TGG & $\begin{array}{l}\text { Lengkong } \\
\text { Regol } \\
\text { Bandung Kidul }\end{array}$ \\
\hline
\end{tabular}

\subsubsection{Penentuan Ring dan Link}

Dari hasil perhitungan lokasi konsentrator menggunakan algoritma Dysart and Georganas[6] ditentukan node LBG sebagai node konsentrator. Dari 9 node termasuk node konsentrator yang menjadi pusat akan dibuat 3 ring dengan ketentuan ring sebagai berikut :

Ring 1 : LBG, HGM, CCD, dan DGO

Ring 2 : LBG, RJW, dan TGA

Ring 3 : LBG, UBR, TGG, dan CJA

Dari ring yang telah ditentukan, pembentukan link yang memungkinkan sangat bervariasi. Oleh karena itu, dalam penentuan link penghubung harus memilih link yang optimal yaitu dengan jarak tempuh yang paling minim. Pemilihan link mengunakan TSP dalam penyambungan node bertujuan untuk mendapatkan jarak traveling yang optimal. Pada penelitian ini menggunakan algoritma Brute Force dikarenakan jumlah node yang tidak terlalu banyak.

\subsection{Perencanaan Trafik \\ 2.3.1. Peramalan Jumlah Pelanggan dan Pembangkitan Trafik}

Jumlah pelanggan merupakan faktor yang terpenting dalam perencanaan trafik karena pembangkitan trafik setiap node dipengaruhi oleh jumlah pelanggan. Jumlah pelanggan sekarang dan jumlah pelanggan diwaktu yang akan diramalkan perlu diketahui. Pelanggan sekarang dapat langsung diketahui dari sumber terkait yang dalam hal ini didapatkan dari service provider PT Telkom Indonesia dan Badan Pusat Statistik (BPS). Akan tetapi, untuk jumlah pelanggan pada waktu yang akan diramalkan perlu diketahui nilai pertumbuhan pelanggan berdasarkan history yang telah lampau kemudian dihitung proyeksi pelanggan dengan pertumbuhan geometri untuk menentukan jumlah pelanggan dimasa mendatang.

Pada penelitian ini pelanggan dibedakan menjadi 4 jenis berdasarkan kebutuhan trafik yaitu : pelanggan perorangan, industri sedang, industri besar dan perguruan tinggi.

$$
\begin{aligned}
& P_{t}=P_{o}(1+r)^{t} \\
& \text { Keterangan : } \\
& P t=\text { jumlah penduduk pada tahun } t \\
& P o=\text { jumlah penduduk pada tahun dasar } \\
& t=\text { jangka waktu } \\
& r=\text { laju pertumbuhan penduduk }
\end{aligned}
$$

Pendistribusian trafik secara merata sesuai pembangkitan trafik pernode dengan cara berikut ini [2].

$$
\begin{aligned}
& H G M-D G O \\
& =H G M \times \frac{D G O}{H G M+D G O+C C D+U B R+R J W+L B G+T G A+T G G+C J A}
\end{aligned}
$$

\subsubsection{Estimasi Trafik Point to Point Forecast}

Estimasi trafik pada penelitian ini menggunakan pembobotan Rapp's 1, Rapp's 2 dan Australian Telecom[7]. Perhitungan trafik didasarkan pada data jumlah pelanggan tahun awal, trafik tahun awal, dan jumlah pelanggan tahun yang akan diramalkan.

$$
A_{i j}(t)=A_{i j}(0) \frac{W_{i} G_{i}+W_{j} G_{i}}{W_{i}+W_{j}}
$$

Faktor pembobot (W) digunakan 3 cara pendekatan yaitu metode Rapp's 1, Rapp's 2 dan Australian Telecom.

- Metode Rapp's 1

$W_{i}=N_{i}(t)$

$W_{j}=N_{j}(t)$

- Metode Rapp's 2

$W_{i}=N_{i}(t)^{2}$

$W_{j}=N_{j}(t)^{2}$

- Metode Australian Telecom

$W_{i}=\frac{N_{i}(0)+N_{i}(t)}{2}$

$W_{j}=\frac{N_{j}(0)+N_{j}(t)}{2}$

keterangan

$\mathrm{G}=$ pertumbuhan pelanggan pada suatu sentral

$G_{i}=\frac{N_{i}(t)}{N_{i}(0)}=$ pertumbuhan pelanggan pada sentral $\mathrm{i}$

$G_{j}=\frac{N_{j}(t)}{N_{j}(0)}=$ pertumbuhan pelanggan pada sentral $\mathrm{j}$

$N_{i}(t)=$ jumlah pelanggan di sentral i pada waktu $\mathrm{t}$

$N_{i}(0)=$ jumlah pelanggan di sentral i pada waktu 0

$N_{j}(t)=$ jumlah pelanggan di sentral $\mathrm{j}$ pada waktu $\mathrm{t}$ 
$N_{j}(0)=$ jumlah pelanggan di sentral j pada waktu 0

$W_{i}=$ bobot pada sentral/node $\mathrm{i}$

$W_{j}=$ bobot pada sentral/node

\subsection{Dimensioning Jaringan}

Tujuan utama dari pendimensian jaringan adalah menjamin kebutuhan yang diharapkan dapat terpenuhi secara ekonomis baik untuk pelanggan dan operator[6]. Pendimensian jaringan dilakukan berdasarkan data yang lampau untuk membuktikan bahwa hasil peramalan dapat digunakan untuk kebutuhan dimasa yang akan datang. Hal yang perlu diperhatikan dalam pendimensian adalah utilisasi pada link harus sesuai dengan ketentuan yang telah ditetapkan agar tidak terjadi kemacetan dan overload trafik. Perhitungan kapasitas dilakukan dengan menggunakan persamaan

$R=\frac{V}{A} \times 100 \%$

\section{keterangan}

A $=$ Faktor utilisasi/ Intensitas Trafik

$V=$ Volume trafik = Laju kedatangan paket data $(\mathrm{Gbps})$

$\mathrm{R}$ = Layanan atau bit rate atau kapasitas link (Gbps)

Panduan untuk batas utilisasi kapasitas link yang digunakan PT Telkom diilustrasikan pada Gambar 3. dimana warna hijau merupakan batas utilisasi link masih dalam kondisi baik, sedangkan kuning adalah indikator warning yang menandakan bahwa kapasitas link harus diperbesar. Sedangkan volume trafik berasal dari hasil peramalan menggunakan metode point to point forecast.

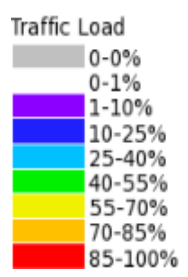

Gambar 3. Indikator Trafik Load

\section{Hasil dan Analisis \\ 3.1. Topologi Jaringan}

Topologi jaringan pada penelitian ini terbentuk berdasarkan algoritma Dysart and Georganas untuk penentuan node konsentrator. Algoritma Brute Force digunakan untuk penyelesaian TSP sehingga membentuk link dan ring yang optimal. Hasil perencanaan jaringan dapat dilihat pada Gambar 4.

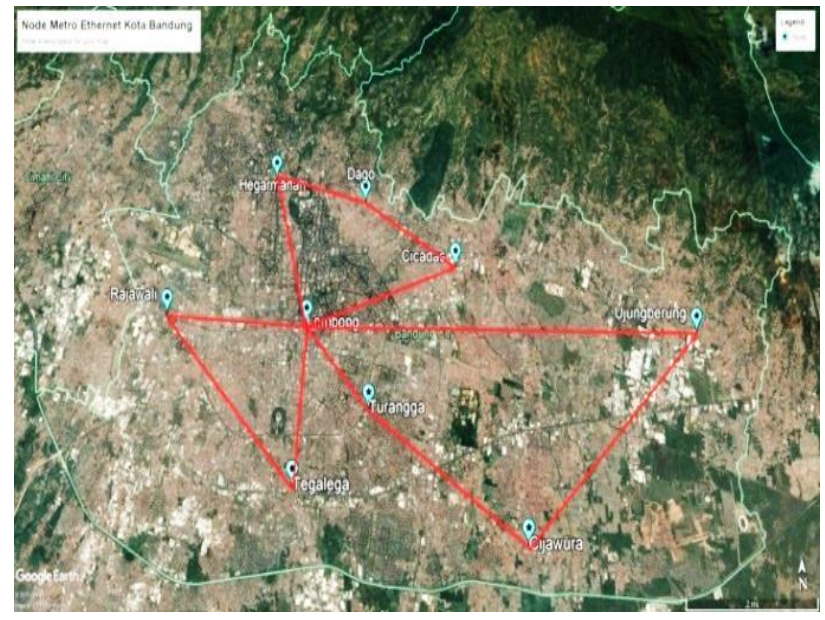

Gambar 4. Topologi Jaringan Metro Ethernet Kota Bandung

\subsection{Peramalan Jumlah Pelanggan}

Berdasarkan hasil survey dari BPS pada beberapa tahun sebelumnya didapatkan nilai rata-rata pertumbuhan yang digunakan sebagai dasar peramalan jumlah pelanggan dari jaringan metro ethernet yang telah dirancang. Rata-rata pertumbuhan pelanggan perorangan setiap tahun Kota Bandung adalah 0,47\%. Rata-rata pertumbuhan pelanggan industri (sedang dan besar) adalah 9,02\%. Rata-rata pertumbuhan pelanggan perguruan tinggi adalah $5,2 \%$.

\subsection{Estimasi Trafik Point to Point}

Estimasi trafik point to point digunakan untuk point to point forecast yaitu peramalan trafik diwaktu yang akan datang berdasarkan jumlah pelanggan pada jaringan[6]. Trafik yang dihasilkan berdasarkan kondisi trafik dan pelanggan saat ini serta pelanggan pada waktu yang akan diramalkan.

Tahun yang menjadi dasar dari forecasting ini adalah tahun 2016, sehingga peramalan dilakukan mulai tahun 2017 hingga 2028. Tujuan peramalan dilakukan setiap tahun dikarenakan untuk mengetahui pertumbuhan trafik setiap tahun.

Hasil peramalan trafik menggunakan metode pembobotan disajikan pada Gambar 4. Untuk metode Rapp's 1, Gambar 5. untuk metode Rapp's 1, dan Gambar 6. untuk metode Australian Telecom. Dapat dilihat bahwa trafik selalu mengalami kenaikan setiap tahunnya. Trafik terbanyak pada link LBG-HGM dan terkecil pada link CJA-TGG 



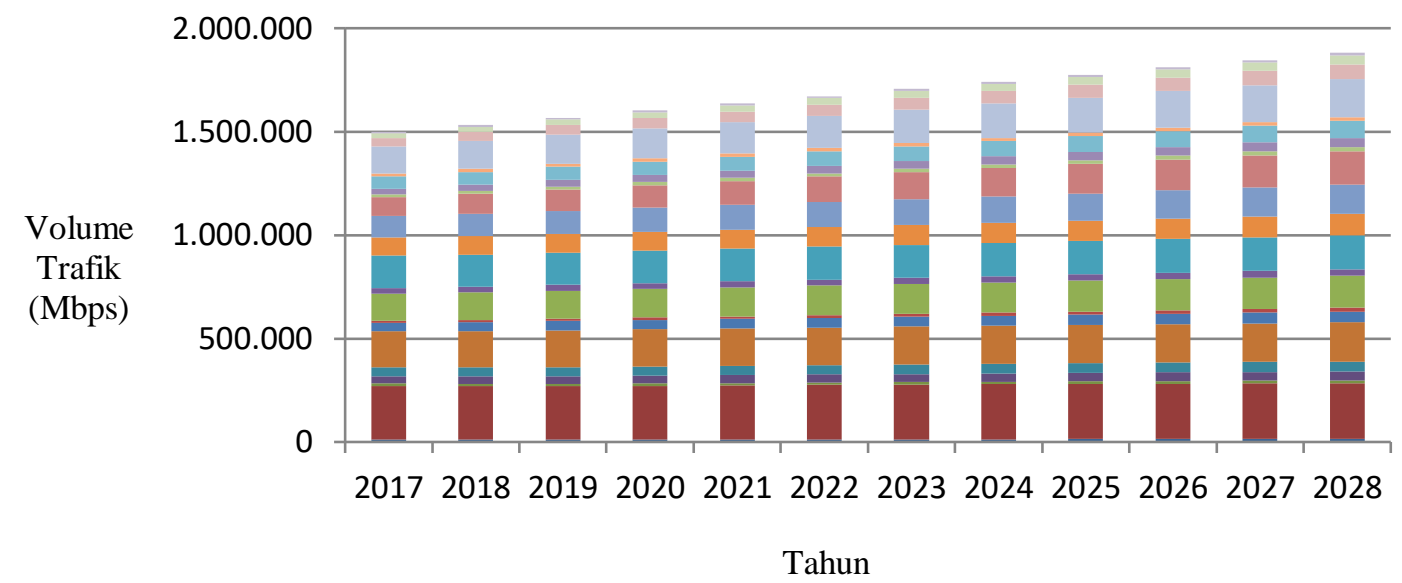

$$
\begin{aligned}
& \text { CJA UBR } \\
& \text { TGG CJA } \\
& \text { TGG LBG } \\
& \text { TGA LBG } \\
& \text { TGA RJW } \\
& \text { LBG TGG } \\
& \text { LBG TGA } \\
& \text { LBG RJW }
\end{aligned}
$$

Gambar 4. Grafik Pertumbuhan Trafik Menggunakan Rapp’s 1

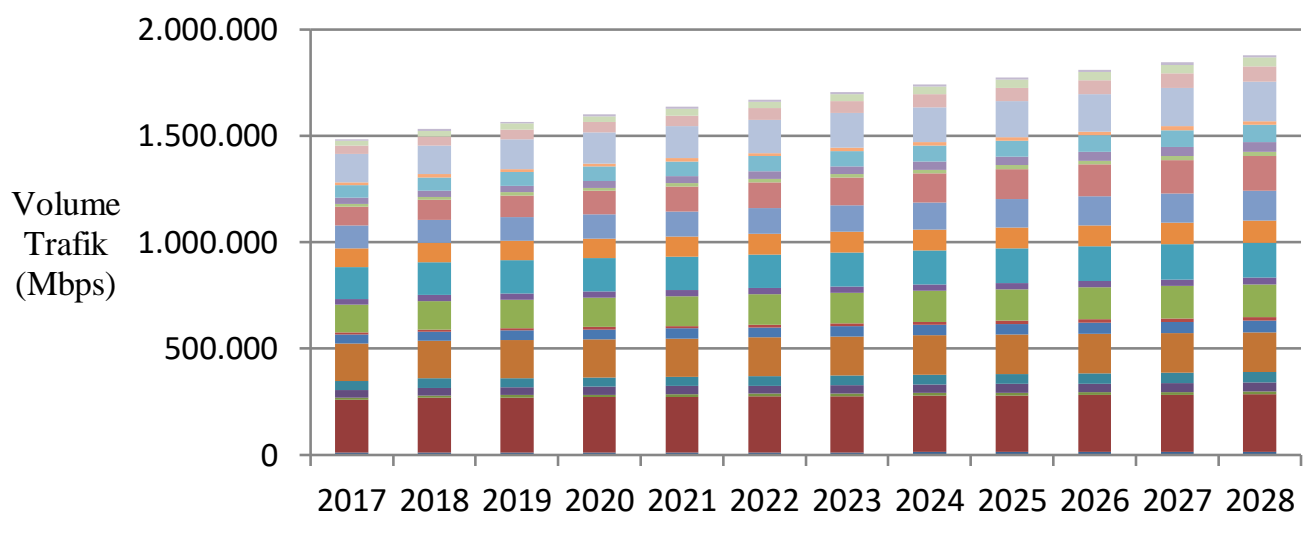

Tahun

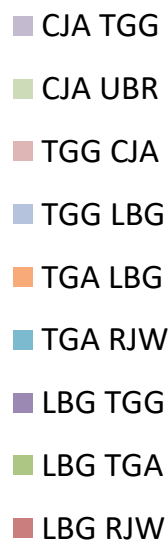

Gambar 5. Grafik Pertumbuhan Trafik Menggunakan Rapp's 2

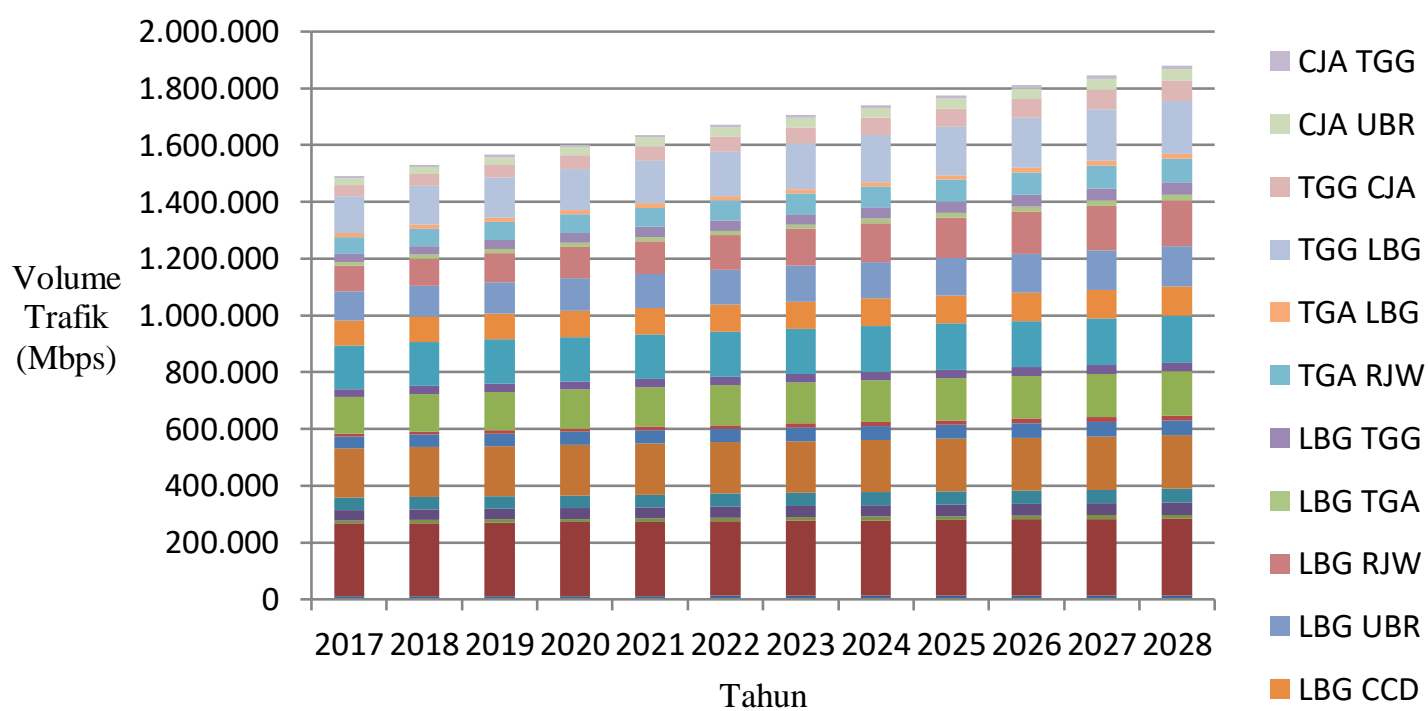

Gambar 6. Grafik Pertumbuhan Trafik Menggunakan Australian Telecom 


\subsection{Utilisasi Kapasitas}

Penelitian ini menggunakan maksimal utilisasi 55\%, hal ini berdasarkan panduan traffic load pada P.T Telekomunikasi Indonesia. Alasan dipilihnya maksimal utilisasi 55\% dikarenakan pada Gambar 2. nilai utilisasi 55\% adalah batas warna hijau yang artinya link masih berjalan lancar. Sedangkan jika nilai diatas $55 \%$ rambu kuning akan muncul dan rambu kuning memiliki arti warning atau peringatan dan jika sudah berada dibatas 85\% maka link akan menjadi rentan terjadi kemacetan dan overload oleh karena itu link harus diganti.

Teknologi yang digunakan pada penelitian ini adalah 40GbE dan 100GbE sesuai dengan standar IEEE 802.3 ba. Kapasitas link yang digunakan juga berdasarkan standar tersebut.
Berdasarkan persamaan (10) perhitungan kapasitas link dapat dicari, sebagai contoh untuk link $\mathrm{HGM} \leftrightarrow \mathrm{DGO}$ dengan volume trafik $27,463 \mathrm{~Gb} / \mathrm{s}$.

$$
\begin{aligned}
R & =\frac{V}{A} \times 100 \% \\
R & =\frac{27,463}{55 \%} \times 100 \% \\
R & =49,932 \mathrm{~Gb} / \mathrm{s}
\end{aligned}
$$

Hasil perhitungan di atas menunjukkan bahwa kapasitas minimal yang dibutuhkan pada link tersebut sebesar $49,932 \mathrm{~Gb} / \mathrm{s}$. Oleh karena itu, pada jaringan digunakan kapasitas $2 \times 40 \mathrm{~Gb}$ agar jaringan tetap berjalan dengan baik.. Hasil penentuan kapasitas pada penelitian ini ditunjukkan pada Tabel 2. sudah sesuai dengan ketentuan yaitu dibawah 55\% dengan utilisasi trafik dua arah

\begin{tabular}{|c|c|c|c|c|c|c|c|c|}
\hline \multirow{3}{*}{ Link dua arah } & \multirow{3}{*}{ Total Trafik } & \multirow{3}{*}{$\begin{array}{c}\text { Minimum } \\
\text { Kapasitas } \\
\text { (utilisasi 55\%) }\end{array}$} & \multirow{2}{*}{\multicolumn{2}{|c|}{$\begin{array}{l}\text { Kapasitas Yang } \\
\text { Disediakan }\end{array}$}} & \multirow{3}{*}{ Utilisasi Liink } & \multicolumn{3}{|c|}{ Trafik Tiap Port } \\
\hline & & & & & & Trafik dua arah & Trafik s & \\
\hline & & & & & & Gbps & Gbps & Utilisasi \\
\hline \multirow{2}{*}{$\mathrm{HGM} \leftrightarrow \mathrm{DGO}$} & \multirow{2}{*}{27,463} & \multirow{2}{*}{49,932} & \multirow{2}{*}{80} & \multirow{2}{*}{$2 \times 40 G$} & \multirow{2}{*}{$34 \%$} & \multirow{2}{*}{13,731} & 7,108 & $18 \%$ \\
\hline & & & & & & & 6,623 & $17 \%$ \\
\hline \multirow{2}{*}{$\mathrm{LBG} \leftrightarrow \mathrm{HGM}$} & \multirow{2}{*}{435,799} & \multirow{2}{*}{792,362} & \multirow{2}{*}{900} & \multirow{2}{*}{$\begin{array}{c}9 X \\
100 G\end{array}$} & \multirow{2}{*}{$48 \%$} & \multirow{2}{*}{48,422} & 30,098 & $30 \%$ \\
\hline & & & & & & & 18,324 & $18 \%$ \\
\hline \multirow{2}{*}{$\mathrm{DGO} \leftrightarrow \mathrm{CCD}$} & \multirow{2}{*}{90,677} & \multirow{2}{*}{164,868} & \multirow{2}{*}{200} & \multirow{2}{*}{$\begin{array}{c}2 X \\
100 G\end{array}$} & \multirow{2}{*}{$45 \%$} & \multirow{2}{*}{45,339} & 21,127 & $21 \%$ \\
\hline & & & & & & & 24,212 & $24 \%$ \\
\hline \multirow{2}{*}{$\mathrm{LBG} \leftrightarrow \mathrm{CCD}$} & \multirow{2}{*}{290,724} & \multirow{2}{*}{528,589} & \multirow{2}{*}{600} & \multirow{2}{*}{$\begin{array}{c}6 x \\
100 G\end{array}$} & $100 \%$ & 10451 & 31,435 & $31 \%$ \\
\hline & & & & & & $40,4 \cup 7$ & 17,019 & $17 \%$ \\
\hline$P G$ & 217523 & 577315 & 600 & $6 x$ & $530 \%$ & 52021 & 25,774 & $26 \%$ \\
\hline LDG↔RJVV & 311,023 & (511,015 & 000 & $100 \mathrm{G}$ & $53 \%$ & $52,9<1$ & 27,147 & $27 \%$ \\
\hline TGA $\mathrm{R}$ IW & 114300 & 207818 & 300 & $3 x$ & $38 \%$ & 38100 & 10,478 & $10 \%$ \\
\hline & & 201,010 & 500 & $100 \mathrm{G}$ & $50 / 0$ & 38,100 & 27,622 & $28 \%$ \\
\hline $1 \mathrm{PC} T \mathrm{TCA}$ & $36-120$ & 66025 & 80 & $2 \times 100$ & $160 \%$ & 10215 & 9,702 & $24 \%$ \\
\hline LBG↔IGA & 36,429 & 66,235 & 80 & $2 \times 40 G$ & $46 \%$ & 18,215 & 8,513 & $21 \%$ \\
\hline IRG & 105060 & 354670 & 400 & $4 X$ & $40 \%$ & 48767 & 35,518 & $36 \%$ \\
\hline$L B G \leftrightarrow U B R$ & (195,069 & $354,6 / 0$ & 400 & $100 \mathrm{G}$ & $49 \%$ & 48,101 & 13,249 & $13 \%$ \\
\hline $\mathrm{CIA} \mathrm{T} G \mathrm{G}$ & 83051 & 151002 & 200 & $2 x$ & $40 \%$ & 11525 & 35,470 & $35 \%$ \\
\hline UJA & & & & $100 \mathrm{G}$ & $4<\%$ & $41,0<0$ & 6,055 & $6 \%$ \\
\hline$I P G \quad T C G$ & 200821 & 117956 & 500 & $5 X$ & $160 \%$ & 15061 & 37,107 & $37 \%$ \\
\hline$L B G \leftrightarrow \mid G G$ & $\angle \angle 9,8 \angle 1$ & 411,050 & 500 & $100 \mathrm{G}$ & $40 \%$ & 45,904 & 8,857 & $9 \%$ \\
\hline URR↔CIA & 59607 & 108.377 & 200 & $2 x$ & $30 \%$ & 29804 & 8,738 & $9 \%$ \\
\hline$U D N \leftrightarrow U J H$ & & & & $100 \mathrm{G}$ & $00 \%$ & 29,004 & 21,066 & $21 \%$ \\
\hline
\end{tabular}
terendah 30\% dan tertinggi 53\%.

Tabel 2. Kebutuhan kapasitas link 


\section{Kesimpulan}

Beberapa kesimpulan yang dapat diambil dari analisa dan pembahasan dari penelitian ini jaringan yang dirancang membentuk tiga ring dengan ring 1 (terdiri dari node LBG, HGM, CCD, dan DGO), ring 2 (terdiri dari node LBG, RJW, dan TGA) dan ring 3 (terdiri dari LBG, UBR,TGG, dan CJA). Penentuan konsentrator menggunakan algoritma Dysart and Georganas menghasilkan LBG sebagai node konsentrator. Algoritma Brute Force untuk penyelesaian TSP dapat menghasilkan link dengan jarak traveling yang terpendek. Link yang terbentuk adalah LBG $\leftrightarrow \mathrm{HGM}, \mathrm{HGM} \leftrightarrow \mathrm{DGO}, \mathrm{DGO} \leftrightarrow$ $\mathrm{CCD}, \mathrm{LBG} \leftrightarrow \mathrm{CCD}, \mathrm{LBG} \leftrightarrow \mathrm{TGA}, \mathrm{TGA} \leftrightarrow \mathrm{RJW}, \mathrm{LBG} \leftrightarrow$ RJW, LBG $\leftrightarrow$ UBR, UBR $\leftrightarrow$ CJA, CJA $\leftrightarrow$ TGG, dan LBG $\leftrightarrow$ TGG. Peramalan trafik yang dilakukan menghasilkan volume trafik yang selalu meningkat setiap tahun antara 173 Mbps hingga 6.908 Mbps. Kenaikan trafik paling tinggi terjadi pada link LBG-RJW yaitu dengan Rapp's 1 sebesar 6.098 Mbps, Rapp's 2 sebesar 6.101 Mbps, dan Australian Telecom sebesar 6.105 Mbps sedangkan kenaikan trafik paling rendah terjadi pada link DGO-HGM dengan Rapp's 1 sebesar 189 Mbps, Rapp's 2 sebesar 173 Mbps, dan Australian Telecom sebesar 199 Mbps.Algoritma Brute Force untuk penyelesaian TSP dapat menghasilkan link dengan jarak traveling yang terpendek.Hasil peramalan dengan metode pembobotan Rapp's 1, Rapp's 2 dan Australian Telecom menghasilkan trafik dengan nilai yang tidak berbeda jauh. Hasil penentuan kapasitas pada penelitian ini sudah sesuai dengan ketentuan dibawah 55\% dengan utilisasi trafik dua arah terendah $30 \%$ dan tertinggi 53\%. Penelitian ini dapat dikembangkan lebih lanjut dengan merancang jaringan metro erthernet antarkota. Pelanggan sebagai pembangkit trafik dapat diperbanyak seperti perkantoran, perhotelan dan pemerintahan agar menghasilkan trafik yang lebih lengkap. Jenis jaringan lain selain metro ethernet dapat menjadi topik lain dalam pengembangan penelitian selanjutnya. Kapasitas link kedepannya dapat diperbesar sesuai dengan teknologi yang sedang berkembang. Penambahan node dan ring yang membentuk jaringan baru dapat menjadi pembahasan penelitian selanjutnya

\section{Referensi}

[1] D. T. Putri, T. Juhana, and S. Haryadi, DWDM system design: DIY-Semarang-Surakarta Ring Proc. - ICWT 2016 2nd Int. Conf. Wirel. Telemat. 2016, pp. 111-116, 2017.

[2] S. Y. Pratama, Analisis Performansi Link Pada Jaringan Metro Ethernet Regional Jawa Tengah Menggunakan Simulator OPNET 14.5. Departemen Teknik Elektro Fakultas Teknik Universitas Diponegoro Semarang. 2016.

[3] M. Apriani, Peramalan Jumlah Pengguna Telepon dan Estimasi Trafik Serta Analisis Parameter Jaringan di PT Telekomunikasi Indonesia. Jurusan Teknik Elektro Program Studi Teknik Telekomunikasi Politeknik Negeri Sriwijaya. Palembang. 2016.

[4] B. Fitranto, Implementasi dan Analisa Spanning Tree Protocol Pada Jaringan Metro Ethernet. Program Studi Teknik Elektro Fakultas Teknik Universitas Mercu Buana. Jakarta. 2015.

[5] Usmiati, Perhitungan dan Pengukuran Layer 1 dan Layer 2 Jaringan Backbone GSM $3 G$ Pada Metro Ethernet Ruas Pasar Seni-Ancol Area Jakarta Utara. Program Studi Teknik Elektro Fakultas Teknik Universitas Mercu Buana. Jakarta. 2012.

[6] Diktat Mata Kuliah Perencanaan Jaringan Telekomunikasi Program Pasca Sarjana Sistem Informasi Listrik ITB

[7] S. Naning Hertiana, Peramalan Trafik untuk Perencanaan Jaringan Sekolah Tinggi Teknologi Telkom

[8] Diktat Mata Kuliah Perencanaan Jaringan Teknik Elektro Universitas Diponegoro.

[9] A. Candra Kharisma, Mengenal Jaringan Metropolitan yang Didasari oleh Teknologi Ethernet (Metro Ethernet Network). Teknik Informatika Fakultas Ilmu Komputer Universitas Sriwijaya fak ilmu komputer. 2009.

[10] PT Telkom Indonesia, Preventive Maintenance Metro Ethernet Huawei,NITS Academy TCU-C Bandung. 2013

[11] Cisco Systems, Metro Ethernet Design Fundamentals Session OPT-1042, Cisco. 2004

[12] V. Mishra, 10 Gigabit Ethenet. Computer Sciene and Engineering School of Engineering Cochi University of Sciene and Technology. 2008.

[13] Moduletek, 40/100 Gigabit Ethernet Overview. Moduletek. 2016. 